\title{
Pengembangan Agrowisata dengan Konsep Design Rainbow Vertical Garden Sederhana di Desa Wisata Rindu Hati
}

\author{
Umi Salamah ${ }^{1}$, Muhimmatul Husna ${ }^{2}$, Refpo Rahman ${ }^{3}$, Ridha Rizki \\ Novanda $^{4}$, Ahmad Syarkowi ${ }^{5}$, Helfi Eka Saputra ${ }^{6}$ \\ ${ }^{1246}$ Fakultas Pertanian, Universitas Bengkulu \\ ${ }^{3}$ Fakultas Matematika dan Ilmu Pengetahuan Alam, Universitas Bengkulu \\ ${ }^{5}$ Fakultas Keguruan dan Ilmu Pendidikan ,Universitas Bengkulu \\ E-mail: umisalamah@unib.ac.id
}

\section{Article History:}

Received: Oktober

2021

Revised: Oktober

2021

Accepted: November

2021

Available

online:Desember 2021

Keywords:

Desa Wisata, Desa

Rindu Hati , PPM,

Vertical Garden,
Abstract: Rindu Hati merupakan desa yang dinobatkan sebagai desa wisata. Kondisi objek wisata Desa Rindu Hati saat ini membutuhkan pengembangan untuk lebih banyak menarik wisatawan. Penambahan objek wisata juga menjaga agar Desa Rindu Hati tetap menjadi pilihan orangorang untuk tetap berekreasi. Rainbow Vertical Garden merupakan konsep agrowisata berbentuk taman mini yang berisi bunga berwarna warni yang digantung pada dinding penegak. Tujuan kegiatan pengabdian ini adalah untuk memperkenalkan dan meningkatkan perkembangan kepariwisataan Desa Rindu Hati sebagai Desa Wisata dengan pengembangan objek wisata baru yaitu Rainbow Vertical Garden. Permasalahan yang dihadapi di desa Rindu Hati adalah pengembangan objek wisata belum ada pengembangan agrowisata yang berbasis pertanian di Desa Rindu Hati. Sasaran utama dari program pengabdian pembinaan ini yaitu Pengelola Wisata Desa Rindu Hati dan Perangkat Desa Rindu Hati. Metode yang dilakukan oleh Tim LPPM UNIB ini merupakan konsep baru yang mengacu pada agrowisata dengan memanfaatkan tanaman hias dengan sistem Rainbow Vertical Garden. Hasil dari kegiatan pengabdian ini adalah mengenalkan masyarakat desa Rindu Hati tentang pemanfaatan Vertical Garden dan pengaplikasian Rainbow Vertical Garden dengan lahan vertikal di Desa Rindu Hati sebagai sebagai agrowisata baru. 


\section{Pendahuluan}

Desa Wisata merupakan bagian dari pengembangan pariwisata yang menampilkan integrasi antara atraksi, akomodasi dan fasilitas pendukung yang disajikan dalam suatu struktur kehidupan masyarakat yang menyatu dengan tata cara dan tradisi yang berlaku. Desa wisata menjadi salah satu kegiatan usaha yang mampu memberikan kontribusi bagi perkembangan dan kemajuan masyarakat desa. Namun dalam perkembangannya, masih banyak hal yang perlu dikaji ulang tentang konsep desa wisata yang berkelanjutan melalui beberpa program yang telah dicanangkan oleh pemerintah. Program Desa Wisata merupakan program unggulan dari Menteri Pariwisata dan Ekonomi Kreatif (Kemenparekraf) Tujuan program pemerintah tersebut adalah mewujudkan perkembangan desa wisata, dari desa tertinggal menjadi desa berkembang sebanyak 10.000 ribu desa, terwujudnya desa berkembang menjadi desa mandiri sebanyak 5.000 desa, terwujudnya revitalisasi kawasan perdesaan sebanyak 60 kawasan perdesaan, terwujudnya revitalisasi kawasan transmigrasi sebanyak 63 kawasan transmigrasi dan terentaskannya daerah tertinggal sebanyak 25 kabupaten tertinggal (Kemendes, 2021).

Rindu Hati merupakan desa yang dinobatkan sebagai desa wisata baru yang ramai oleh wisatawan khususnya hari Sabtu dan Minggu serta hari libur nasional. Di desa yang terletak sekitar $33 \mathrm{~km}$ dari kota Bengkulu itu terdapat setidaknya 11 objek wisata yang bisa didatangi sekaligus seperti wisata sungai Rindu Hati Glamping, Air terjun, Camping Ground, Tubing, Rock Climbing, Persawahan,Telaga putri, Batu kapal, Air terjun Supit, Pemakaman Tuanku Gagok dan Raja Pembesar Alam, dan Rumah Besar Minang.

Kondisi Desa Rindu Hati saat ini membutuhkan pengembangan objek wisata untuk lebih banyak menarik wisatawan datang. Penambahan objek wisata juga menjaga agar Desa Rindu Hati tetap menjadi pilihan orang-orang untuk tetap berekreasi. Penambahan jumlah pengunung menjadi parameter bahwa pengembangan akan desa wisata terbukti. Peramalan jumlah kunjungan wisata yang masuk kedalam suatu daerah sangat diperlukan oleh pelaku bisnis pariwisata (Lestari dan wahyuningsih, 2012). Penarikan pengunjung yaitu melalui penambahan objek wisata baru sebagai tempat untuk berfoto. Pemilihan objek wisata baru harus memiliki inovasi dan kreativitas yang menarik. 
Pengembangan desa wisata dapat mengacu pada konsep agrowisata. Agrowisata merupakan aktivitas wisata yang melibatkan penggunaan lahan pertanian atau fasilitas terkait yang menjadi daya tarik bagi wisatawan (Fadlil, et al., 2020). Pemanfaatan lahan pertanian untuk agrowisata dapat dilakukan pada lahan datar maupun lahan vertical. Pengembangan wisata pada beberapa daerah telah banyak dilakukan seperti objek wisata Edukasi Kampung Tulip di Bandung (Priyanto et al., 2018), Objek wisata kampung Jowo Sekatul di Kabupaten Kendal (Maryam et al., 2011, pengembangan objek wisata objek Kampung Tradisional Bena yaitu dengan menciptakan beragam atraksi kesenian (Osin et al., 2019).

Perkembangan teknologi pertanian kota memunculkan berbagai teknik untuk dapat berkebun di lahan sempit, bahkan di dalam ruangan sekalipun (Asikin et al., 2016). Rainbow Vertical Garden merupakan konsep taman perkotaan yang vertical sehingga tidak membutuhkan tempat yang luas (Wahab dan Munandar, 2018). Konsep agrowisata tersebut berbentuk dari taman mini yang berisi bunga yang berwarna warni yang digantung pada dinding penegak. Penataan taman vertikal adalah susunan tanaman yang disusun sedemikian rupa dalam bidang yang tegak lurus atau mendekati tegak lurus sebagai taman dalam waktu yang relative lama. Dalam penataannya tetap memadukan unsur softscape (tanaman) dan unsur hardscape (bebatuan, besi, stepping stone, dan lain-lain). Tanaman yang digunakan merupakan tanaman yang mudah ditemui, merupakan tanaman yang umum dan mudah dikembangkan sehingga supply tanaman tidak perlu dikhawatirkan. Tanaman yang dipilih biasanya tanaman yang disesuaikan dengan vertical garden yang akan dibuat, karena penempatannya dapat dilakukan di dalam ruangan dan luar ruangan.

Secara sosial vertical garden memberikan pemandangan yang bagus, nuansa alam bagi hidup dan estetika yang menarik (Ghoustanjiwani et al., 2011). Rainbow Vertical Garden tidak membutuhkan space yang luas. Penempatan bunga-bunganya tidak membutuhkan area khusus. Penempatan taman dapat diletakkan di pinggir jalan atau pada gerbang masuk. Penambahan taman dengan sistem akan menambah nilai jual dari Desa Wisata Rindu Hati.

Tujuan kegiatan pengabdian ini adalah untuk memperkenalkan dan meningkatkan perkembangan kepariwisataan Desa Rindu Hati sebagai Desa Wisata dengan pembuatan Rainbow Vertical Garden. Selain itu, manfaat dari kegiatan pengabdian ini adalah untuk meningkatkan nilai jual bagi Desa 
Rindu Hati dengan mempertahankan suatu pariwisata tidak mudah dilakukan sehingga perlu ada upaya yang mendorong agar kondisinya tetap terjaga. Manfaat lain yaitu untuk meningkatkan perekonomian bagi masyarakat pedesaan. Selain manfaat pengembangan desa sebagai desa wisata dalam hal tingkat hidup masyarakat serta pelestarian budaya, manfaat yang akan diterima oleh masyarakat selanjutnya adalah tentu saja dalam hal perekonomian.

\section{Metode}

\section{Lokasi dan Waktu Pengabdian}

Kegiatan pengabdian dilaksanakan di Desa Rindu Hati, Bengkulu Tengah pada Agustus sampai Oktober 2021.

\section{Alur Kegiatan Pengabdian Pada Masyarakat}

Kegiatan pengabdian masyarakat di Desa Rindu Hati memiliki beberapa tahapan kegiatan dari kegiatan awal hingga akhir kegiatan.

\begin{tabular}{|l|l|l|l|}
\hline $\begin{array}{l}\text { Perizinan } \\
\text { kegiatan di } \\
\text { Desa Rindu } \\
\text { Hati }\end{array}$ & $\begin{array}{l}\text { Sosialisasi dan } \\
\text { pengenalan tentang } \\
\text { Rainbow Vertical Garden } \\
\text { kepada masyarakat desa } \\
\text { wisata Rindu Hati }\end{array}$
\end{tabular}

Metode yang dilakukan pada kegiatan Pengabdian Pada Masyarakat (PPM) oleh LPPM UNIB sebagai berikut:

1. Izin kegiatan pengabdian kepada Perangkat Desa Rindu Hati. Izin pelaksanaan kegiatan dilakukan pada dua minggu sebelum kegiatan berlansgung. Izin kegiatan awal adalah langkah untuk memberikan informasi tentang semua kegiatan berlangsung.

2. Sosialisasi dan pengenalan tentang Rainbow Vertical Garden kepada pengelola desa wisata Rindu Hati sebagai agrowisata baru. Di awal kegiatan ini tim penabdian bekerjasama dengan masyarakat setempat untuk berpartisipasi dalam menyediakan bunga. Dalam kegiatan tersebut dihasilkan kesepakatan lokasi tempat pembuatan Rainbow Vertical Garden. Tempat yang akan dibuat Rainbow Vertical Garden merupakan kesepakatan oleh pengelola objek wisata dan perangkat desa Rindu Hati. 
Lokasi kegiatan berada di tempat yang mudah diakses oleh pengunjung yang datang yaitu berada di dekat pintu masuk.

3. Pengaplikasian Rainbow Vertical Garden di Desa Rindu Hati

Tahapan pelaksanaan kegiatan pembuatan Rainbow Vertical Garden adalah sebagai berikut ini:

3.1 Persiapan bunga warna warni

Bersana - sama dengan masyarakat menyiapkan alat dan bahan yang digunakan yaitu berupa bibit bunga warna warni, pot bunga, media tanam berupa tanah, sekam dan pupuk kandang, kayu ukuran $1 \mathrm{~m} \mathrm{x}$ $1,6 \mathrm{~m}$, kawat ram, kwat penyangga pot, paku dan pengait.

\subsection{Pembuatan taman vertikal}

a. Membuat dinding sebagai miniatur taman untuk penyangga bunga. Membuat bingkai yang terbuat dari kayu berukuran $1,1 \mathrm{~m}$ x $1,6 \mathrm{~m}$. Kemudian pasang kawat ram sebagai badan untuk dinding bunga dengan ukuran $1 \mathrm{mx} 1,5 \mathrm{~m}$ (menyesuaikan dengan bingkai)

b. Membuat dua kaki penyangga setinggi $1,5 \mathrm{~m} \times 1,5 \mathrm{~m}$.

c. Penanaman bunga-bunga dalam pot Bunga yang diambil adalah bunga yang sudah tumbuh bukan dalam benih. Bunga ini didapatkan dari tim pengabdian dan bekerjasama dengan masyarakat. Berikut tahapan yang dilakukan untuk menanam bunga dalam pot

- Memilih media tanam / pot yang baik.

- Mencampurkan tanah, sekam dan pupuk dengan perbandingan $2: 1: 1$

- Memasukan bunga yang akan ditanam.

- Menambahkan tanah dan pupuk hingga tanaman tersebut terpendam dengan baik.

d. Meletakkan tanaman pada intensitas sinar matahari yang cukup.

e. Penyusunan bunga ke dinding penyangga sebagai taman vertikal.

Pot yang sudah terisi bunga dipasang di dinding dan susun dengan rapi. Pot ditali dengan kawat supaya kuat. Bunga-bunga yang disusun terdiri dari 3 jenis warna bunga. Pembagian ketiga jenis bunga tersebut adalah membentuk huruf "RH" dengan, di luar tulisan $\mathrm{RH}$ dan pembatas antar huruf $\mathrm{R}$ dan $\mathrm{H}$.

f.Perawatan taman vertikal

Bunga yang sudah ditanam harus dilakukan perawatan. Perawatan yang dilakukan adalah penyiraman bunga dilakukan sehari dua kali dan pemberian nutrisi berupa pupuk untuk tanaman. 


\section{Dharma Raflesia}

Jurnal Ilmiah Pengembangan dan Penerapan IPTEKS

Vol. 19, No. 02, Desember, 2021, pp. 356 - 371

4. Evaluasi kegiatan adalah memantau masyarakat untuk tetap menjaga bahwa taman vertical garden tetap terjaga dengan baik.

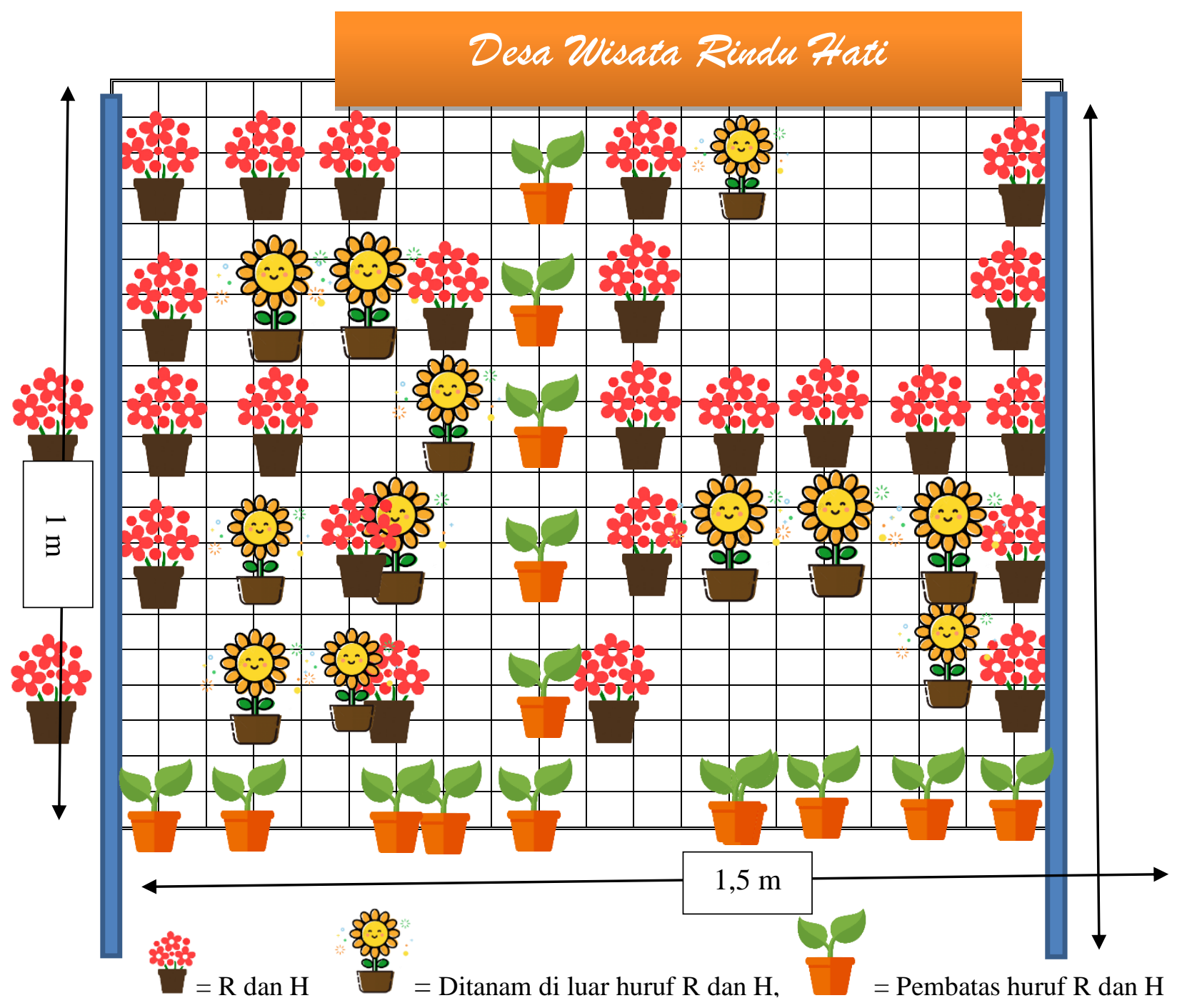

Gambar 1. Design Rainbow Vertical Garden 


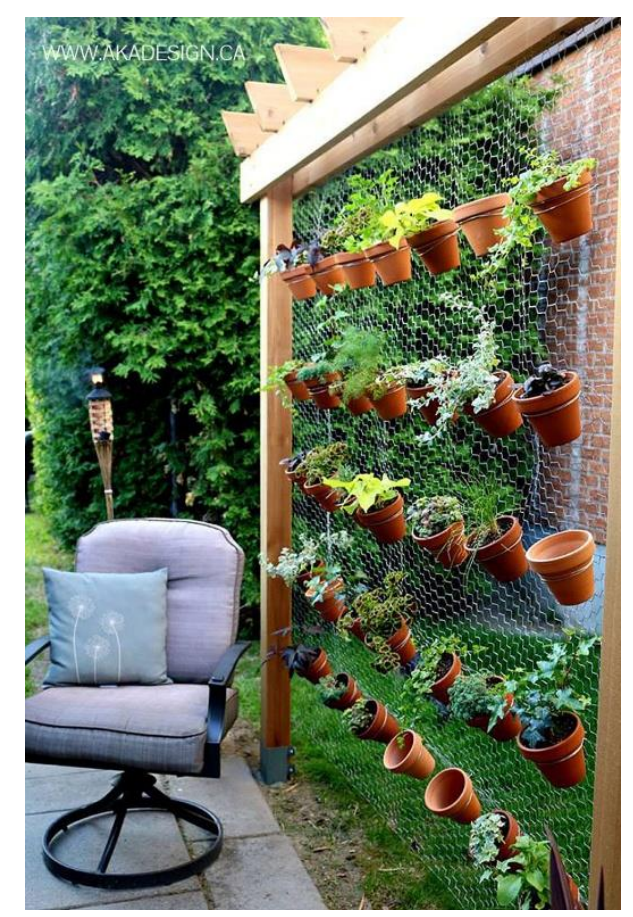

Gambar 2. Susunan Rainbow Vertical Garden (sumber: https://homebnc.com/homeimg/2016/05/02-create-an-airy-gardenbackdrop-with-simple-chicken-wire-vertical-gardens-homebnc.jpg)

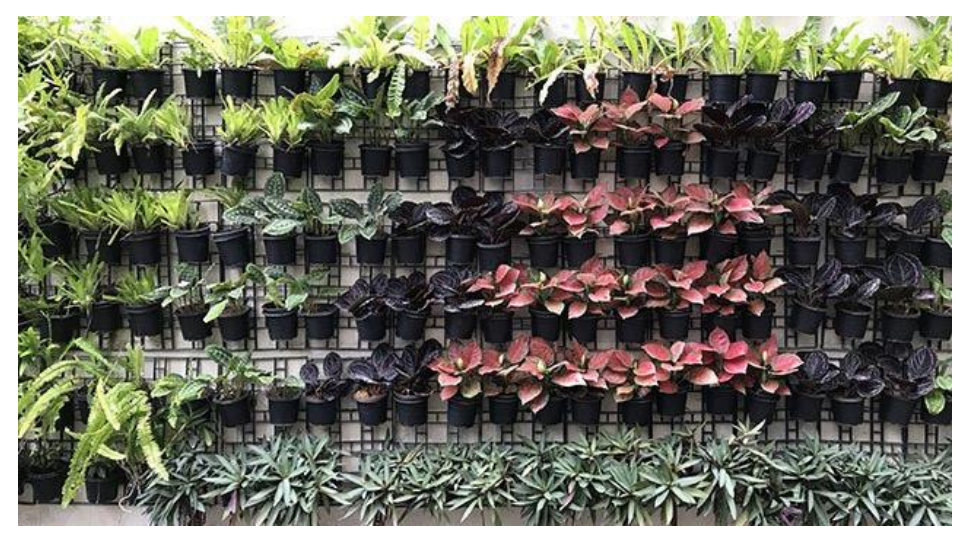

Gambar 3. Jenis pot yang akan digunakan dengan bunga yang warna warni (sumber: https://www.99.co/blog/indonesia/wpcontent/uploads/2019/04/taman-vertikal-8.jpg) 


\section{Teknik Pengambilan data}

Pengambilan data dilakukan melalui observasi, wawancara dan studi dokumentasi.

\section{Hasil}

Berdasarkan hasil kegiatan yang telah dilaksanakan Berikut adalah pencapaian kegiatan PPM yang dilaksanakan oleh tim dari Universitas Bengkulu di Desa Rindu Hati yaitu:

a. Kegiatan pertama yang dilakukan adalah melakukan perizinan dengan kepala Desa Rindu Hati. Kegiatan perizinan dilakukan untuk membicarakan tentang jadwal pelaksanaan kegiatan dan tema kegiatan yang akan dilaksanakan. Penetapan jadwal kegiatan dimaksudkan untuk memberitahukan kepada warga desa Rindu Hati akan adanya kegiatan ini.

b. Kegiatan kedua adalah sosialisi untuk kegiatan pemanfaatan Rainbow Vertical Garden di Desa Rindu Hati. Bentuk kegiatan ini adalah metode ceramah yang disampaikan kepada masyarakat Desa Wisata Rindu Hati. Kegiatan sosialisasi dimaksudkan untuk mengenalkan kepada masyarakat Desa Rindu Hati akan potensi wisata yang dimiliki oleh desa tersebut.

c. Kegiatan ketiga adalah pengaplikasian Rainbow Vertical Garden di Desa Rindu Hati.

d. Kegiatan keempat adalah mengevaluasi kegiatan dan memastikan bahwa rainbow vertical garden tetap terjaga dengan baik.

\section{Diskusi}

\section{a. Gambaran umum Desa Wisata Rindu Hati}

Desa Rindu Hati memiliki wilayah yang sangat luas yaitu 5.837,27 hektar, dengan peruntukan terdiri atas permukiman penduduk 6,64 hektar, perkebunan karet rakyat 35,33 hektar, persawahan 87,47 hektar, areal penggunaan lain 16,85 hektar, kebun campuran dan hutan sekunder 5.398,52 hektar, hutan belukar 22,28 hektar, dan hutan primer seluas 279,16 hektar (Monografi Desa Rindu Hati, 2010: 9-11). Berdasarkan Sensus Penduduk Tahun 2010 penduduk Desa Rindu Hati berjumlah 1.172 jiwa, terdiri atas laki-laki 559 jiwa dan perempuan 613 jiwa atau 361 kepala keluarga. Pencaharian utama penduduk desa bergerak di bidang pertanian (Hamdani et al, 2015).

Desa Rindu Hati sebagai desa wisata yang sedang berkembang sangat membutuhkan dukungan dari berbagai pihak. Dukungan tersebut berasal dari 
LSM, kampus, pemerintah, perusahaan dan lain sebagainya. Dalam hal ini Universitas Begkulu sebagai kampus yang memiliki peran serta dalam proses kehidupan bermasyarakat memiliki keikutsertaan dalam membangun kemajuan desa Rindu Hati. Universitas Bengkulu melalui kegiatan pengabdian masyarakat memberikan kontribusi terhadap perkembangan pariwisata daerah.

Desa Rindu Hati sudah memiliki objek wisata antara lain air terjun, arung jeram, dan dampling. Objek wisata yang ada masih tergolong sedikit untuk dimiliki sebagai ikon desa wisata. Desa erat kaitannya dengan dunia pertanian sebagai kegiatan masyarakat desa. Warga desa Rindu hati yang sebagian besar adalah berprofesi petani. Hali ini mengindikasikan bahwa kehidupan pertanian bukanlah hal yang asing lagi bagi masyarakat Desa Rindu Hati. Namun objek wisata yang menempati desa mereka belum menyentuh dunia pertanian. Pemilihan Vertical Garden memperkenalkan kepada masyarakat Desa Rindu Hati tentang konsep taman pada lahan vertical. Inovasi ini diharapkan menarik perhatian pengunjung guna meningkatkan jumlah wisatawan.

\section{b. Pemilihan Vertical Garden sebagai penambahan objek wisata baru di Desa Rindu Hati}

Pemilihan Vertical Garden dimaksudkan untuk menjadi tambahan objek wisata yang berguna dalam menarik wisatawan yang berkunjung ke daerah tersebut. Vertical Garden pada umumnya digunakan di lingkungan perkotaan sebagai taman pada dinding rumah karena lahan pertanian semakin sempit. Universitas Bengkulu menjadi fasilitator untuk dapat menerapkan Rainbow Vertical Garden di Desa Rindu Hati.

Dilihat dari nilai estetikanya Vertikal Garden terlihat sangat indah karena tersusun dari berbagai macam bunga yang tertata dengan rapi. Hal tersebut tidak menutup kemungkinan untuk dapat diterapkan pada daerah wisata yang banyak didatangi oleh pengunjung. Rainbow vertical garden diperuntukkan kepada wisatawan yang berkunjung. Mereka dapat menjadikan tempat ini sebagai wahana berfoto. Karena saat ini spot foto adalah tempat yang dicari oleh pengunjung yang berwisata sehingga harus menampilkan sesuatu yang unik. 
Kegiatan pengabdian masyarakat oleh tim LPPM-UNIB di Desa Rindu Hati disambut dengan antuasias oleh warga. Para warga terlihat bersemangat untuk membuat taman rainbow vertical garden. Para warga bersepakat untuk meletakkan taman tersebut di tempat yang sangat strategis yaitu pinggir jalan sehingga banyak pengunjung yang langsung tertuju pada taman tersebut. Persiapan lokaasi diperlukan dalam hal ini. Menurut Hidayat (2011) menyatakan bahwa optimalisasi penyiapan sarana dan prasarana dibutuhkan untuk mendukung pengembangan wisata.

Bersama-sama masyarakat Desa Rindu Hati dan Tim LPPM untuk menyusun bunga-bunga ke dalam pot dan kemudian diletakkan vertical garden. Vertical garden merupakan kebun yang didesain membentuk arah vertikal atau bertingkat sehingga dapat mengoptimalkan lahan yang ada. Taman vertikal dapat ditanami dengan sayuran dengan masa panen yang cepat sehingga dapat menghemat pengeluaran atau sebagai green bank (penghijauan). Selain itu, taman vertikal dapat disusun secara bertingkat sehingga menambah estetika kebun di pekarangan rumah (Sari et al., 2014). Menurut Luddityawan et al., (2014) bahwa konfigurasi taman vertikal paling efektif adalah konfigurasi dengan penataan 6 tingkat dan jarak 1 meter.

Penggunaan pot dalam kegiatan ini adalah menggunakan pot yang memiliki telinga sehingga memudahkan kaitkan dengan kawat. Pot yang digunakan juga bisa memanfaatkan barang bekas seperti botol minuman yang tidak terpakai, hal ini seperti yang dilakukan oleh Asropah et al,. (2016) pada kegiatan PPM di Desa Sarirejo, Semarang.
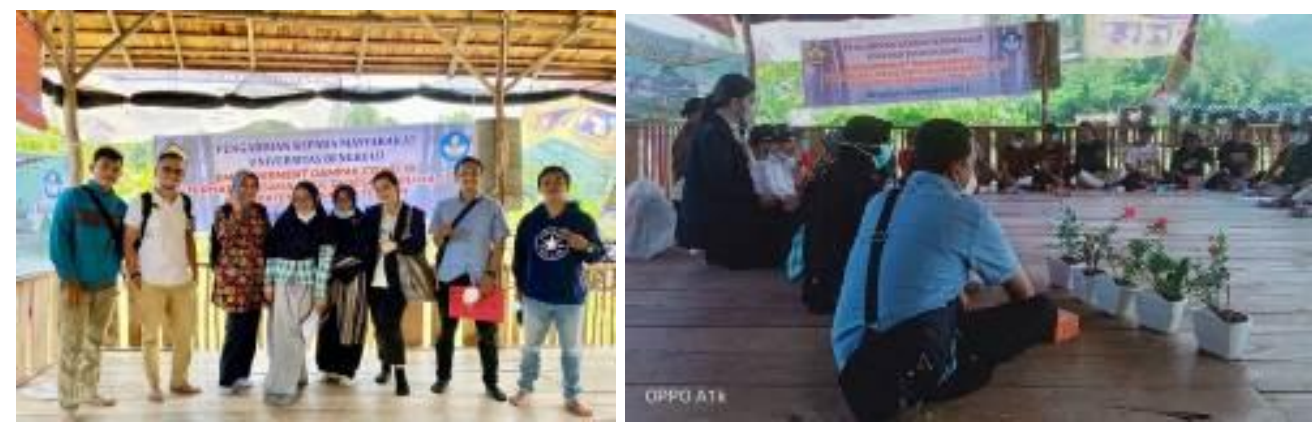


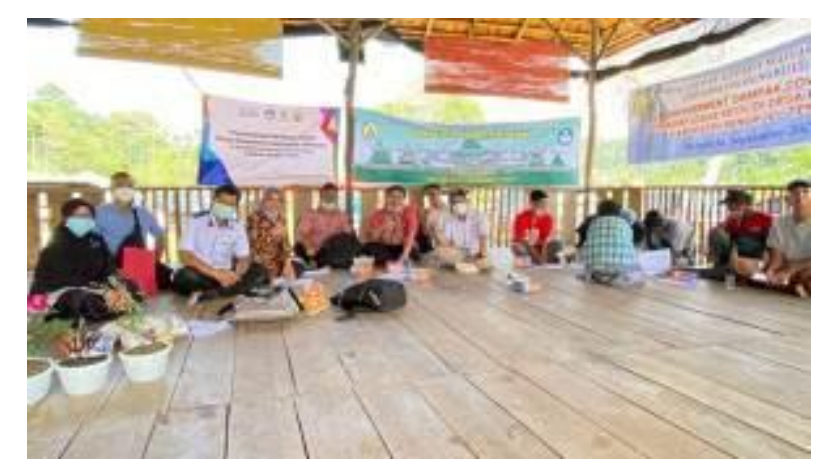

Gambar 4. Kegiatan sosialisasi Rainbow Vertical Garden di Desa Rindu Hati oleh Tim Pengabdian Pada Masyarakat Universitas Bengkulu

Kegiatan ini berupa praktik langsung kepada masyarakat untuk membuat dan menyusun taman. Tanaman yang digunakan adalah bunga yang berisi 3 jenis bunga yang berbeda yaitu bunga yang menghasilkan bunga mawar merah, bunga Aglonema, dan bunga levonero kalatea. Ketiga bunga ini dipilih karena merupakan jenis bunga yang berbeda dan warna dan coraknya memiliki kekontrasan. Jenis bunga ini dikelompokkan menjadi 2 kelompok, yaitu:

a. Bunga yang menghasilkan bunga yaitu bunga mawar merah

b. Bunga yang hanya berdaun yaitu bunga berdaun Calathea ornata (bergaris ungu merah), dan bunga levonero kalatea (berdaun hijau).

Pemilihan bunga untuk Vertical Garden dapat dilakukan pada jenis Philodendron'Moonlight', Aechmea fasciata, Tradescantia zebrina, Chlorophytum comosum, Dracaena surculosa, Tillandsia usneoides, dan Nephrolepis cordifolia (Chaipong, 2020).

Bunga-bunga tersebut perlu dirawat dengan baik yaitu dengan memberikan nutrisi yang tepat. Menurut Iswanto (2002) media tanam yang baik untuk tanaman hias harus memenuhi kriteria antara lain; tidak mudah lapuk, tidak mudah menjadi sumber penyakit, aerasi baik,mampu mengikat air dan unsur hara dengan baik (Gunawan, 2000), mudah didapat dan harga relative murah. Menurut Andalasari et al., (2014) bahwa Penggunaan pupuk Gandasil lebih baik pada bunga anggrek. 


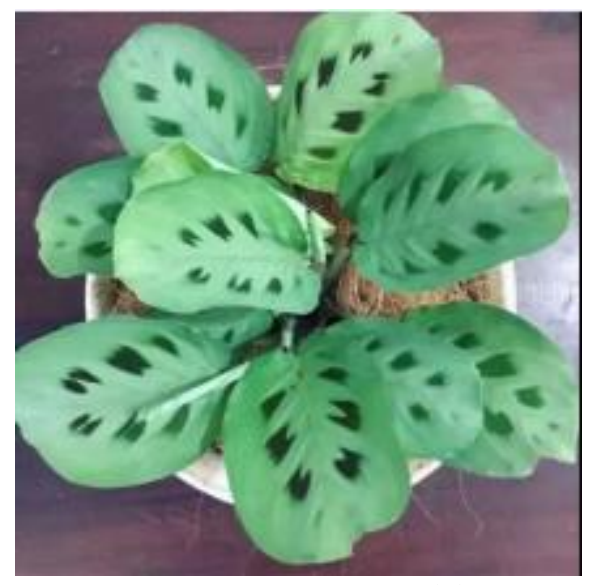

(a)

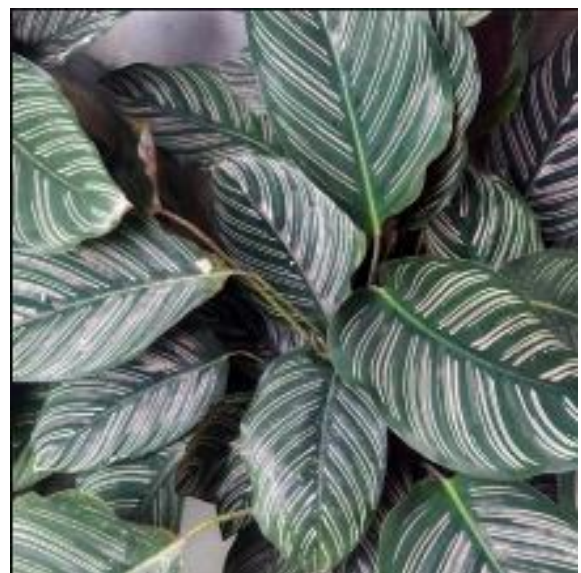

(b)

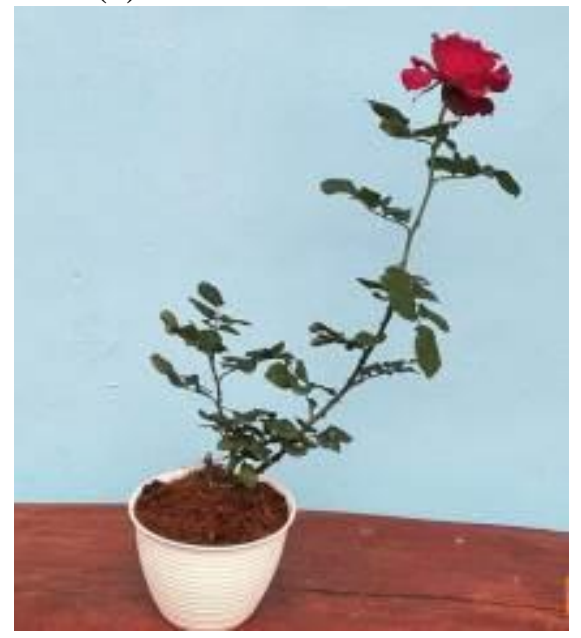

(C)

Gambar 5. Bunga untuk vertical garden: (a) levonero kalatea; (b) Calathea ornate, dan (c) bunga mawar merah

Kerangka vertical garden terbuat dari kawat besi dan diberi tiang kayu yang dicat berwarna merah tua. Diberikan tulisan "RINDU HATI" di bagian atas. Bunga-bunga tersebut ditanam dalam pot berwarna putih. Kemudian disusun di kerangka dengan menggunakan kawat. Masyarakat sangat antusias mengikuti kegiatan PPM ini.

Evaluasi kegiatan adalah memantau masyarakat yang ditunjuk sebagai pengelola wisata untuk dapat menjaga dan merawat taman yang mereka miliki. Beberapa pengunjung telah mengenali tempat tersebut dan mengabadikannya dalam foto. Vertical Garden menjadi pariwisata baru di 
Dharma Raflesia

Jurnal Ilmiah Pengembangan dan Penerapan IPTEKS

Vol. 19, No. 02, Desember, 2021, pp. $356-371$

Desa Rindu Hati. Pariwisata akan memberi dampak positif bagi kehidupan ekonomi masyarakat seperti menciptakan peluang kerja baru, meningkatkan kesempatan berusaha, meningkatkan pendapatan masyarakat lokal, meningk atkan pendapatan daerah melalui retrubusi dan pajak dan lain sebagainya (Hermawan, 2016)
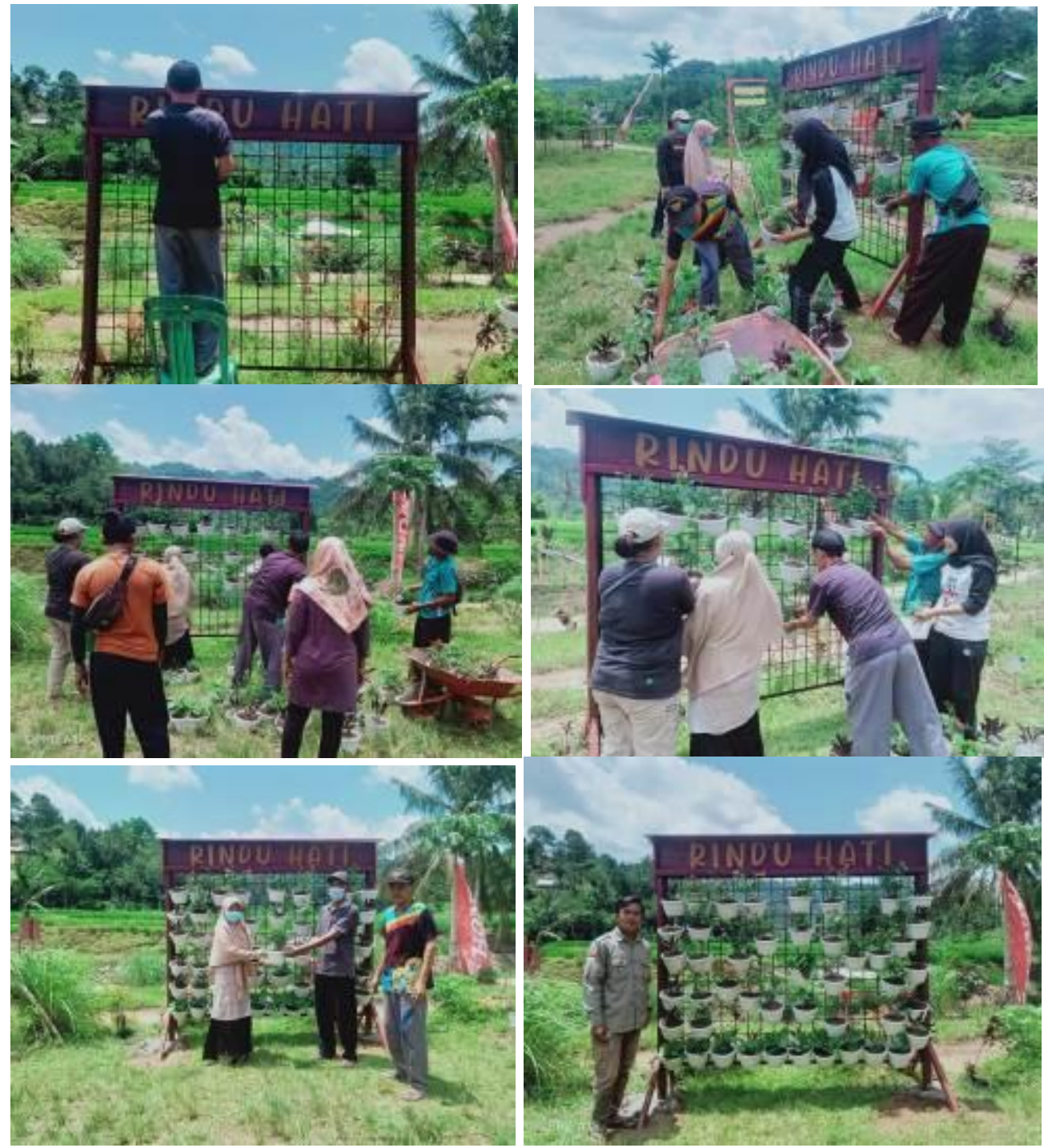

ISSN : 1693-8046 (PRINT), ISSN: 2615-4544

(ONLINE) 

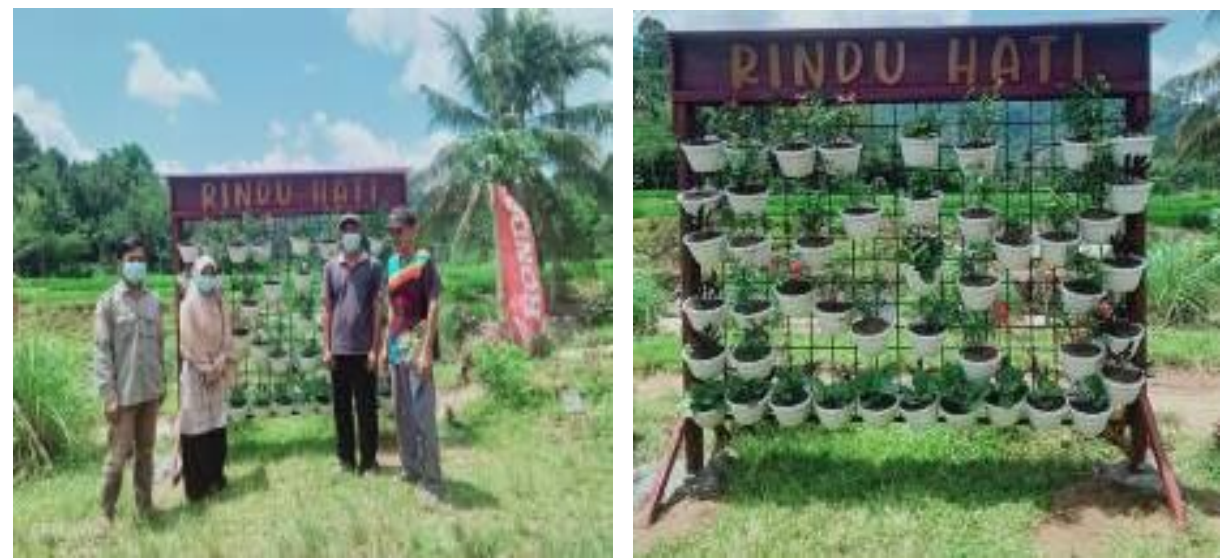

Gambar 6. Penerapan Kegiatan Rainbow Vertical Garden di Desa Rindu Hati

\section{Kesimpulan}

Berdasarkan hasil kegiatan yang telah dilaksanakan, kegiatan PPM ini yaitu meliputi sosialisasi tentang pemanfaatan Vertical Garden dan pengaplikasian Rainbow Vertical Garden dengan lahan vertikal di Desa Rindu Hati sebagai sebagai agrowisata baru.

\section{Pengakuan/Acknowledgements}

Ucapan terimakasih kepada Lembaga Pengabdian Pengabdian Masyarakat Universitas Bengkulu (LPPM) yang telah memfasilitasi dalam kegiatan pengabdian bidang pembinaan di Desa Rindu Hati.

\section{Daftar Referensi}

Andalasari, T. D., Yafisham, Y., \& Nuraini, N. (2014). Respon Pertumbuhan Anggrek Dendrobium terhadap Jenis Media Tanam dan Pupuk Daun. Jurnal Penelitian Pertanian Terapan, 14(1).

Asikin, D., Handayani, R. P., \& Mustikawati, T. (2016). Vertical Garden dan Hidroponik sebagai Elemen Arsitektural di Dalam dan di Luar Ruangan. RUAS (Review of Urbanism and Architectural Studies), 14(1), 3442.

Asropah, A., Septiana, I., \& Indrariani, E. A. (2016). Pemanfaatan Barang Bekas Botol Plastik dalam Pembuatan Vertical Garden. E-Dimas: Jurnal Pengabdian kepada Masyarakat, 7(2), 9-16. 
Chaipong, S. (2020). Indoor Plant Species Survival Under Different Environment in Indoor Vertical Garden. International Journal of Geomate, 18, 15-20.

Fadlil, M. A., Sumekar, W., \& Mardiningsih, D. (2020). Strategi Pengembangan Agrowisata Berbasis Bunga Krisan (Chrysanthemum Morifolium R.) di Taman Bunga Celosia, Desa Candi Kecamatan Bandungan Kabupaten Semarang. Jurnal Ekonomi Pertanian dan Agribisnis, 4(1), 39-50.

Ghoustanjiwani, A. P., Kusmara, R., \& Yanuar, W. (2011). Teknologi Vertical Garden: Sustainable Design atau Hanya Sebuah Trend dalam Urban Life Style.

Gunawan L. W. 2000. Budidaya Anggrek. Penebar Swadaya. Jakarta. 86 hlm.

Hamdani., M. Yamani., dan E. Septaria. (2016). Menemukan Model Solusi Pendayagunaan Tanah Pertanian Terlantar Di Desa Rindu Hati Kabupaten Bengkulu Tengah. Monograf. Program Studi Pascasarjana Ilmu Hukum, Fakultas Hukum UNIB, Bengkulu

Hidayat, M. (2011). Strategi perencanaan dan pengembangan objek wisata (studi kasus pantai Pangandaran Kabupaten Ciamis Jawa Barat). THE Journal: Tourism and Hospitality Essentials Journal, 1(1), 33-44.

Hermawan, H. 2016. Dampak Pengembangan Desa Wisata Nglanggeran Terhadap Ekonomi Masyarakat Lokal. Jurnal Pariwisata, III(2)

Iswanto Hadi. 2002. Petunjuk Perawatan Anggrek. Agromedia Pustaka. Jakarta. 65 hlm

Kemendes. 2021. Kemendes PDTT targetkan 10.000 desa tertinggal menjadi desa berkembang. https://kemendesa.go.id/berita/view/detil/3505/kemendes-pdtttargetkan-10000-desa-tertinggal-menjadi-desa-berkembang

Lestari, N., \& Wahyuningsih, N. 2012. Peramalan Kunjungan Wisata dengan Pendekatan Model Sarima (Studi Kasus: Kusuma Agrowisata). Jurnal Sains dan Seni ITS, 1(1), A29-A33.

Luddityawan, A. R., Nugroho, A. M., \& Razziati, H. A. 2014. Taman Vertikal Sebagai Pendinginan Alami Pada Rumah Sederhana Sehat Griya Saxophone Kecamatan Lowokwaru-Kota Malang. Jurnal Mahasiswa Jurusan Arsitektur, $1(1)$.

Maryam, S., \& WARIDIN, W. (2011). Pendekatan SWOT dalam pengembangan objek wisata kampoeng djowo sekatul kabupaten kendal (Doctoral dissertation, Universitas Diponegoro).

Osin, R. F., Kusuma, I. R. W., \& Suryawati, D. A. (2019). Strategi Pengembangan Objek Wisata Kampung Tradisional Bena Kabupaten Ngada-Flores Nusa Tenggara Timur (NTT). Jurnal Ekonomi dan Pariwisata, 14(1).

Priyanto, R., Syarifuddin, D., \& Martina, S. (2018). Perancangan Model Wisata Edukasi di Objek Wisata Kampung Tulip. Jurnal Abdimas BSI: Jurnal Pengabdian Kepada Masyarakat, 1(1). 
Sari, M., Ai Nurjanah, Lidhia Fairuz Harly. 2014. Vertical Garden sebagai Green Bank dalam Usaha Optimalisasi Lahan pada Kawasan Lingkungan Padat Penduduk di Kota Bandung Jawa Barat. Universitas Pendidikan Indonesia Bandung. Bandung.

Wahab, D. A., \& Munandar, T. (2018). Smart vertical garden application on exterior building supporting environment. In IOP Conference Series: Materials Science and Engineering, 407, (1), IOP Publishing. 